\title{
Narrativas de vida e formação de professores gays: (auto) biográficas acerca do estranho que habita em mim
}

\author{
Narratives of life and training of teachers gays: (auto)biographical \\ about the weird that lives in me
}

Pedro Paulo Souza Rios*

Universidade do Estado da Bahia
Edonilce Rocha Barros**

Universidade do Estado da Bahia

Andre Ricardo Lucas Vieira***

Universidade do Estado da Bahia

Resumo $\mathrm{O}$ presente estudo tem por objetivo analisar, por meio de narrativas (auto)biográficas, as histórias de vida de professores homossexuais, na tentativa de compreender as nuances dos processos formativos implicados na história de vida e formação dos mesmos. Compreendemos assim, que as narrativas (auto)biográficas, enquanto perspectiva epistemológica, se apresentam como um instrumento rico de auto formação, uma vez que o ambiente escolar deve se constituir em um espaço e em uma educação menos desigual, mais humanizadora e que potencialize as habilidades humanas. Conhecer aspectos do percurso da vida pessoal e profissional construídos pelos professores foi uma experiência singular. Compreendemos assim, que as narrativas (auto)biográficas, enquanto perspectiva epistemológica, se apresentam num instrumento rico de auto formação, uma vez que o ambiente escolar deve se constituir em um espaço formativo de respeitos às diferenças.

PALAVRAS-CHAVE: Homossexualidade; Formação de professores;

Narrativas.

Abstract The purpose of this study is to analyze the life histories of homosexual teachers through (auto)biographical narratives in an attempt to understand the nuances of the formative processes involved in the life history and formation of the same. Thus, we understand that (auto)biographical narratives, as an epistemological perspective, are presented in a rich instrument of self-formation, since the school environment must constitute a less unequal space, a more humanizing education, Human beings. Knowing aspects of the course of personal and professional life built by teachers was a unique experience. The narrative was presented in another experience and this contributed significantly to the realization of rich and productive reflections about the formation and its life trajectories. Thus, we understand that (auto) biographical narratives, as an epistemological perspective, present themselves in a rich instrument of self-formation, since the school environment must constitute a formative space of respect for differences.

KEYWORDS: Homosexuality; Teacher training; Narratives. 


\section{Introdução: considerações acerca da estranheza}

A prática sexual sempre foi motivo da curiosidade humana e tal prática, quando se trata de pessoas do mesmo sexo torna a curiosidade ainda mais latente. Deseja-se adentrar na intimidade alheia com o intuito de punir, por mera curiosidade ou por vontade de experienciar. As questões relacionadas à sexualidade e/ou a prática sexual na história da humanidade, sempre foram motivo de especulação e análise, despertando interesse das mais diferentes áreas do conhecimento.

Comumente os problemas da esfera da sexualidade são tratados enquanto problemas que dizem respeito à esfera da moral, assim, a orientação sexual se configura enquanto desvio de caráter e, nessa lógica, apenas a heteronormatividade ${ }^{1}$ se enquadra dentro dos padrões morais considerados normais socialmente. A homossexualidade, nesse contexto, é considerada anormal, sendo pertinente ressaltar que tal concepção faz parte de um arcabouço cultural, dicotômico, que tem por princípios os valores sociais e morais da cultura Ocidental e cristã.

A saber, na mitologia grega, Iolaos, representa um herói divino tebano, considerado um Eromenoi ${ }^{2}$, prezado por sua modéstia, esforço e coragem. Iolaos era visto, constantemente, abraçado com rapazes.

$\mathrm{O}$ mito se relaciona às escolhas sexuais, considerando vivências, informações, preconceitos, conceitos, concepção de mito e de verdades decodificados na infância, sendo concebido enquanto processo dinâmico e contínuo, onde precisamos aprender a lidar com a nossa sexualidade. Na mitologia grega, acolher os desejos é expressar a individualidade, aonde os sujeitos vão se constituindo livremente. Nesse contexto, as questões inerentes à sexualidade devem ser consideradas e aceitas como algo natural que fazem parte do desenvolvimento do ser humano e de sua evolução.

O presente estudo se propõe analisar, por meio de narrativas autobiográficas, as histórias de vida, suas trajetórias escolar, acadêmica e profissional, entrelaçando essas às vivências subjetivas e identitárias de professores homossexuais, para compreender as nuances dos processos formativos implicados na história de vida e formação dos mesmos.

Assim, acreditando ser a escola um reflexo ativo da sociedade, de que maneira esse ambiente lida com professores cuja orientação sexual é a homossexualidade? Como as questões de gênero e sexualidade vivenciadas por professores gays influenciam em seu processo de formação e em sua prática docente?

No que concerne aos fundamentos metodológicos, optamos pela pesquisa de caráter qualitativo. A metodologia utilizada será a pesquisa narrativa, no campo educacional, por valorizar e explorar as dimensões pessoais dos sujeitos, seus afetos, sentimentos e trajetórias de vida e levando à percepção da complexidade das interpretações que os sujeitos pesquisados fazem de suas experiências e ações, sucessos e fracassos e dos problemas que enfrentam. Enquanto instrumento de pesquisa, as narrativas (auto)biográficas encontram sentido e razão de serem, no fato de que a história de vida de uma pessoa tende a desvelar elementos para além de simples acontecimen- 
tos, caracterizando-se como forma de absorção e análise dos contextos que constituem histórica e humanamente cada sujeito, uma vez que todas as narrações autobiográficas relatam um corte horizontal ou vertical, uma práxis humana (FERRAROTTI, 2014). De acordo com Souza (2014, p. 42) "Narrativas (auto)biográficas configuram-se como corpus de pesquisa, visto que são recolhidas de forma oral e/ou escrita”.

No processo de construção das narrativas (auto)biográfica dos professores, utilizamos a entrevista narrativa, no período de novembro de 2015 a maio de 2016, onde procurou-se estabelecer encontros individuais, com horários previamente estabelecidos, considerando a disponibilidade de tempo. Em comum, eles apresentam o fato de se assumirem enquanto professores homossexuais, serem concursado na rede pública de ensino e trabalharem com as Séries Iniciais do Ensino Fundamental II.

\section{Homossexualidade: um tabu contemporâneo}

Contemporaneidade é um conceito de origem latina, com-temporaneu, que significa viver na mesma época, particularmente a atual (HOUAISS, 2001). $\mathrm{O}$ advento da contemporaneidade trouxe em seu bojo uma pauta que pensávamos já ser algo superado. Lutas travadas na década de 1960, que pensávamos ser algo superado, tais como direito das mulheres, feminismo, direito à diversidade, etnia, liberdade sexual dentre outros, vêm garantindo notoriedade na construção do conhecimento e dos direitos humanos na atualidade.

Estudos de caráter social no campo da homossexualidade, por exemplo, têm seu marco inicial no século XX. Até então a homossexualidade era considerada doença e, portanto, deveria ser tratada enquanto patologia (GAMSON, 2007). Ao longo dos tempos, em diferentes contextos sociais e culturais, a homossexualidade foi motivo de punição, vergonha, segregação e violência contra todos aqueles que atravessassem a fronteira da heteronormatividade.

O antropólogo Luiz Mott (2003), destaca a importância de estudos acerca da homossexualidade na realidade brasileira. Para ele, tais estudos significam a possibilidade de desvendar as raízes do preconceito em nossa sociedade, contribuindo para erradicar a intolerância e a crueldade contra os homossexuais. As variadas formas de expressões e manifestação da multiplicidade da sexualidade humana ainda é um problema presente e constante na chamada contemporaneidade, caracterizado pela diversidade, principalmente se tratando das identidades de gênero e orientação sexual LGBT (lésbicas, gays, bissexuais, travestis e transexuais). Ressalta Mott que,

Adentrar-se na intimidade do sexo de um ser humano, sobretudo em se tratando de um homossexual, sempre é importante, pois como durante os últimos quatro milênios nossa civilização tachou o amor entre pessoas do mesmo sexo de abominação, pecado mortal e crime, havendo um orquestrado complô do silêncio que até nossos dias impede a divulgação desta variável amorosa. (MOTT, 2003, p. 23).

Estudos em torno das questões da homossexualidade e, consequentemente, a desconstrução dos papéis sexuais do feminino e masculino, vêm buscado repensar a 
representação e os discursos de identidade, que circulam no arcabouço do saber/poder presente nas reações sociais, de tal modo que possamos repensar, refletir e reconstruir o discurso da própria sexualidade, pautada meramente na concepção binária das relações.

Nenhuma identidade sexual - mesmo a mais normativa - é automática, autêntica, facilmente assumida. Nenhuma identidade sexual existe sem negociação ou construção. Não existe, de um lado, uma identidade heterossexual lá fora, pronta, acabada, esperando para ser assumida e, de outro lado, uma identidade homossexual instável, que deve se virar sozinha. Em vez disso, toda identidade sexual é um construto instável, mutável e volátil, uma relação social contraditória e não finalizada (BRITZMAN, 1996, p.74).

Os mitos, contemporâneos, criados em torno da homossexualidade, acabam por estabelecer noções normativas que atribuem à heterossexualidade o status de sexualidade estável e natural, portanto, "normal", classificando como anormal toda e qualquer manifestação sexual ou de gênero fora dos padrões estabelecidos pela heteronormatividade.

Criam-se artifícios que inviabilizam o sujeito homossexual de vivenciar com plenitude seus direitos como cidadão. Scott (1986), Britzman (1996), Louro (1997) chamam atenção para o fato de que tanto a hetero quanto a homossexualidade são construções sociais e culturais e, portanto, não é algo determinado meramente por fatores biológicos.

A escola se configura numa das instituições nas quais se instalam mecanismos do dispositivo da sexualidade, sendo ela uma das múltiplas instâncias sociais que exercitam uma pedagogia da sexualidade e do gênero (LOURO, 2007), havendo um investimento continuado e produtivo desses sujeitos na determinação de suas formas de ser ou formas de viver sua sexualidade e seu gênero.

\section{A fala do corpo, o silêncio da escola: educação e diversidade}

Gay, viadinho, mulherzinha, bichinha, maricona são conceitos pejorativos que marcam e demarcam a vida e o corpo de meninos gays ainda na infância. Palavras que anunciam em alto e bom som seus modos de ser e de viver. Ser homossexual, reconhecer-se homossexual, traz à tona a revolução dos tempos, jeito de ser e de viver, sentimentos, sonhos, corpos de milhares de sujeitos que se (re)constroem e se (re) inventam diariamente no fazer cotidiano.

Compreendemos a escola, enquanto espaço de formação, como um importante instrumento no enfrentamento de situações de preconceito e discriminação, contudo, mesmo com a implementação dos Parâmetros Curriculares Nacionais - PCN's e as significativas transformações que estão acontecendo na sociedade e no campo educacional brasileiro, observa-se que os currículos têm dado pouca importância às questões relativas ao gênero e a diversidade sexual, reproduzindo lógicas perversas de opressão contra as identidades LGBT.

Nos PCN's, a orientação sexual é entendida pelo viés informativo, o que está vinculado à visão de sexualidade que perpassa o documento. A sexualidade é concebida como um dado da natureza, portanto, "algo inerente, necessário e fonte de pra- 
zer na vida”. É perceptível o destaque atribuído às diferenças entre meninos e meninas. Diferenças essas, consideradas como sendo social e culturalmente construídas, mas, em nenhum momento, elas são problematizadas, evidenciando meramente a oposição entre os gêneros em detrimento dos papéis atribuídos social e culturalmente a meninos e meninas. Conforme Louro (2003, p. 57), a escola, desde a sua origem, entende e produz “diferenças, distinções, desigualdades" sociais, étnicas, geracional, de gênero, de orientação sexual dentre outras.

A negação dos/as homossexuais no espaço legitimado da sala de aula acaba por confiná-los às "gozações" e aos "insultos" dos recreios e dos jogos, fazendo com que, desse modo, jovens gays e lésbicas só possam se reconhecer como desviantes, indesejados e ridículos (LOURO, 2003, p. 68).

Os saberes para a prática pedagógica onde se pode combater a homofobia converte-se em uma questão para qual a escola deve estar aberta, afim de poder produzir conhecimento em forma de credenciar as/os professoras/es no combate à homofobia, ou seja, a escola deve ser a principal base de combate na luta. Inverter esse quadro no cotidiano escolar deve ser para a escola e o educar um marcador de divisão.

\section{Percurso metodológico: trilhas da construção/formação da identidade de professores gays}

Para esse estudo consideramos que a fenomenologia se configura no método mais apropriado, considerando que esse procedimento metodológico, objetiva construir uma compreensão acerca do fenômeno estudado mediante a captação da intencionalidade revelada nos relatos. De acordo com Moreira (2002, p. 108) “o método fenomenológico enfoca os fenômenos subjetivos na crença de que verdades essenciais acerca da realidade são baseadas na experiência vivida. (...) O que interessa é a experiência vivida no mundo do dia-a-dia das pessoas".

Compreender a trajetória de vida de professores gays, tendo por pressupostos a narrativa a partir dos processos formativos é o que propomos nesta pesquisa, pois entendemos que os sujeitos em sua formação profissional precisam estabelecer conexões e desenvolver competências não somente com o fazer pedagógico, essas são necessárias também nas relações sociais que se estabelece com os contextos específicos (NÓVOA, 1992).

Nossa investigação será em torno da narrativa (auto)biográfica, focando a formação, assim, optamos por trabalhar com instrumentos de pesquisa que nos permitissem investigar essas relações em profundidade. Considerando as características da pesquisa, ressaltamos a importância de estarmos abertos e flexíveis para captar a importância do significado daquela informação específica para responder nossa questão orientadora do estudo. Estamos falando das abordagens qualitativas em pesquisa na educação.

As narrativas (auto)biográficas, enquanto instrumento e procedimento de pesquisa, encontram sentido e razão de serem, no fato de que a história de vida de uma pessoa tende a desvelar elementos para além de simples acontecimentos, caracte- 
rizando-se como forma de absorção e análise dos contextos que constituem histórica e humanamente cada sujeito, uma vez que todas as narrações autobiográficas relatam um corte horizontal ou vertical, uma práxis humana (FERRAROTTI, 2014).

O interesse pelas narrativas autobiográficas no meio científico tem sido de grande relevância, já que aborda a perspectiva dos sujeitos face às estruturas e aos sistemas, da qualidade face à quantidade, da vivência face ao instituído (NÓVOA, 2000). Assim, a pesquisa baseada em narrativas (auto)biográficas, afirma-se como possibilidade de tomar a experiência humana como objeto de conhecimento, passivo de mensuração, análise e interpretação.

Pesquisas que tenham por base as narrativas (auto)biográficas, no plano da interioridade, a pessoa que narra se deixa levar pelas associações livres para evocar as suas experiências e organizá-las numa coerência narrativa em torno da sua formação e, no plano da exterioridade, a socialização da autodescrição de um caminho, com as suas continuidades e rupturas, envolve competências verbais e intelectuais que estão na fronteira entre o individual e o coletivo (JOSSO, 2004).

Nas últimas décadas, a investigação centralizada nas histórias de vida, na educação, tem conquistando significativa visibilidade. As pesquisas nessa área de conhecimento adotam "as narrativas de formação como um movimento de investigaçãoformação, seja na formação inicial ou continuada de professores/professoras ou em pesquisas centradas nas memórias e autobiografias de professores" (SOUZA, 2006, p. 137).

Nessa perspectiva, Souza (2006) afirma que o trabalho centrado na abordagem (auto)biográfica, como uma prática de investigação/formação, se justifica pela constante relação "dialética entre as dimensões prática e teórica, as quais são expressas através da meta-reflexão do ato de narrar-se, dizer-se de si para si mesmo como uma evocação dos conhecimentos das experiências construídos pelos sujeitos" (p. 140).

As narrativas aqui analisadas são resultados das reuniões do GENESESertaneja ${ }^{3}$, entre maio 2015 e junho de 2016. Vale ressaltar que essa não foi uma tarefa fácil. As conversas informais, mantidas até então, de certa maneira desenhava o tom de "deboche" e risos reflexivos acerca da própria história. Agora, diante de um gravador, numa conversa a dois, entre o sujeito que narra e o que ouve, outros contornos foram desenhados.

As entrevistas foram gravadas individualmente, com datas e horários previamente combinados, com duração entre trinta e cinquenta minutos cada uma, sendo gravadas em média duas entrevistas com cada um dos professores. É pertinente ressaltar que após a gravação e transcrição, as narrativas foram socializadas nas reuniões do GENESESertaneja. De acordo com Souza (2008),

Tomar a escrita de si como um caminho para o conhecimento, numa perspectiva hermenêutica, não se reduz a uma tarefa técnica ou mecânica. O pensar em si, falar de si e escrever sobre si emergem em um contexto intelectual de valorização da subjetividade e das experiências privadas. Neste sentido, o conceito de "si mesmo" é, como todo conceito, uma proposta organizadora de determinado princípio de racionalidade (SOUZA, 2008, p. 44). 
Cada lembrança, cada fala, era seguida de uma reflexão sem julgamentos, uma autoanálise após longos anos de afastamento do objeto agora em cena: homossexualidade. Compreendo que o ato de falar de si pode restaurar o sentimento de domínio de sua própria vida, da mesma forma que pode recuperar a integralidade de sua personalidade (Catani, at al. 1997), ao tempo em que se configura em fonte de conhecimento na formação de professores/as.

Considerando as narrativas dos professores, elegemos três categorias de análises: 1) "Professora, ele é diferente da gente: "A diferença que não cabe na escola"; 2) Colorindo a escola: "Esse espaço é meu também" e; 3) Ser um professor diferente: "Pedagogia da inclusão".

\section{Os sujeitos da pesquisa: arte de fazer-se}

A escolha dos sujeitos se deu a partir de um levantamento prévio, realizado pelo GENESESSertaneja, onde optou-se por analisar as narrativas de dois professores da rede pública municipal, residentes no Território de Identidade Piemonte Norte do Itapicuru, no Semiárido Brasileiro. Como critério de escolha dos professores, levou-se em consideração maior tempo na docência e formação superior concluída. Em comum os professores apresentam as seguintes características: gays, formação em pedagogia, há mais de dez anos na docência e trabalham com as Séries Iniciais do Ensino Fundamental II.

No que se refere à identificação dos sujeitos, acordou-se em manter o anonimato. Assim, serão utilizados nomes fictícios escolhidos pelos mesmos, durante reunião do GENESESertaneja, a partir de árvores nativas do Semiárido Brasileiro.

Professor Juazeiro ${ }^{4}$ conta que "desde pequeno eu sempre fui muito... muito gay! Não tem outra palavra pra dizer" e continua ele: "mas além de ser gay, eu sempre quis ser professor e isso me incomodava. Como pode um gay ser professor? Sabe como é...?”.

Nesse mesmo sentido, o professor Umbuzeiro ${ }^{5}$ relata "Eu nunca tive esse perfil muito feminino, naturalmente, apesar de ter percebido desde muito cedo, ainda criança que eu era... assim... homossexual". Após um momento de silêncio continua ele: "mas eu queria ser professor e pensava que por ser gay tinha algo estranho".

\section{"Professora, ele é diferente da gente": a diferença que "não" cabe na escola}

Historicamente, a escola, enquanto instituição educativa, não foi pensada e estruturada para acolher a diferença. Mulheres, negros/as, homossexuais, trabalhadores/as, prostitutas e tantas outras categorias foram sendo colocados à margem dos processos educativos (LOURO, 2007). Conforme sinaliza o professor Juazeiro,

Eu sempre me senti um peixe fora d'água na escola. Algumas lembranças me doem até hoje. Eu era literalmente um estranho, sabe como é? Você passa e todo mundo aponta, diz alguma coisa, solta uma piada ou sussurra baixinho e você sente que é sobre você [...]. 
Eu tinha raiva de ir pra escola quando eu era criança. A professora mandava eu endurecer a munheca e gritava que desmunhecar era coisa de homem que não prestava e meus colegas riam de mim me chamando de mulherzinha. Tem uma frase que os meninos diziam direto: 'professora, ele é diferente da gente'.

Nessa mesma perspectiva o professor Umbuzeiro conta que "Gostava de estudar. Sabe aquela história de estudar pra ser alguém? Pois é, eu carregava isso comigo: queria ser alguém, mas eu não gostava de ir pra escola [...]. Me sentia enjaulado".

As narrativas evidenciam práticas educativas pautadas únicas exclusivamente na heteronormatividade, por meio de métodos que punem verbal fisicamente, reforçando a todo instante que a escola não é lugar para a diferença. Nessa perspectiva, Louro (2004) sinaliza que a escola é por natureza um espaço de conflito, já que se propõe a ser um espaço democrático, contudo, acaba por determinar quem permanece e quem sai.

A dificuldade no que diz respeito à diversidade sexual no âmbito escolar pode ser compreendida, principalmente, pela maneira como os currículos vêm pensados e estruturados, perpetuando práticas educativas vinculadas a lógicas heterossexistas e por fim, ao desconforto dos profissionais de educação frente ao tema. Para o professor Umbuzeiro,

A escola não tá nem aí para aquele aluno que é "diferente”, ela pensa nos iguais. Agora me diz se isso é possível? As diferenças... como é que eu posso dizer? As diferenças em todos os sentidos: gay, negro, mulher, deficiente, travestis, toda e qualquer diferença não consegue ficar muito tempo na escola e permanecer sendo diferente [...]. Ou a gente entra no jogo, ou... caso contrário você vive se torturando o tempo todo [...]. E tem todo um sistema na base de tudo isso. É difícil!

Daí a necessidade de se pensar a formação docente pautada nos pilares da educação para a diversidade, mediante investimentos na capacitação de profissionais durante o ensino superior, na formação continuada e, sobretudo, na incorporação desses conteúdos na estrutura curricular. Uma vez que o/a professor/a se coloca enquanto sujeito mediador/a e organizador/a do processo pedagógico deve favorecer a visão de conjunto sobre a situação, e propõe outras fontes de informação, colocando o aluno em contato com outras formas de pensar as questões de gênero e sexualidade.

\section{Colorindo a escola: "esse espaço é meu também"}

Compreendemos que a escola se configura num importante instrumento social de adestramento dos corpos. Assim, acabam por constituir as identidades de gênero e as formas de ser e de viver a masculinidade e a feminilidade, a homossexualidade e a heterossexualidade. Contudo, o que se tem percebido é que os sujeitos "diferentes" acabam por criar mecanismos de sobrevivência dentro dos espaços escolares, por considerar que os mesmos são seus por direito.

Chega um dia que a gente já não aguenta mais ser humilhado. As pessoas apontam o tempo inteiro como a gente deve se comportar... Lembro como se fosse hoje: um dia cheguei na escola lacrando ${ }^{6}$, 
como dizem hoje, e disse que as pessoas precisavam me respeitar e que a partir daquele dia eu não ia mais abaixar a cabeça. Já que eu servia para organizar os eventos da escola, agora era a hora da escola aprender a me respeitar, pois a escola também era minha [...] e aî tudo melhorou. Claro que ainda ouvi piadinhas, mas depois muitos passaram a ter medo de mim (Professor Juazeiro).

A narrativa do professor Juazeiro evidencia um posicionamento político, uma vez que o mesmo agora passa a demarcar um território, que mesmo sendo seu de direito, foi necessária sua re-apropriação. Quando ele afirma: "Esse espaço também é meu!", e ao fazer isso, ele conquista, ainda que à “força”, o respeito daqueles/as que durante anos o perseguiu.

É pertinente dizer que a escola sempre foi um território de disputa, conflitos e de jogo de interesses, onde historicamente prevalecia a vontade da burguesia (ARROYO, 2011), conforme sinaliza o professor Umbuzeiro,

Tive vários embates na minha época de escola... sabe como é, né? Não que eu quisesse, mas era necessário. Quando era pra organizar as festas da escola e os eventos, a diretora, as professoras chamava logo a gente. Os gays da escola eram sempre os primeiros da lista, mas na era de representar a escola em atividades mais sérias os "viados” nunca eram escolhidos, sempre ia os mais ricos. Sabe aquela coisa estereotipada? Era bem assim, mas a gente demarcava espaço.

Louro (2007) questiona a forma com que os educadores encaram a discussão da sexualidade, pois muitos pensam que se deixar de tratar desses problemas, a sexualidade ficará fora da escola. O professor Juazeiro relata: "A professora gritava comigo: 'aqui dentro da escola você tem que se comportar, lá fora seja o que for aqui dentro todo mundo é igual'. E eu me perguntava: como isso é possível?”. Ficando evidenciado que a escola não reproduz ou reflete as concepções de gênero e sexualidade que circulam na sociedade, mas ela própria as produz.

Interessante... depois que o tempo passa a gente começa a lembrar certas coisas [...] por mais que a escola dissesse que não era pra gente, no caso os meninos que tinham os trejeitos, se comportassem assim... como posso dizer? Como mulher, é isso, ela acaba por incentivar isso na gente. Era a gente que deixava a escola mais alegre, mais viva, sabe como é? Por mais que quisesse nos repreender, a escola acabava nos libertando (Professor Juazeiro).

Compreendemos o espaço escolar enquanto território que deve subsidiar a construção da autonomia e da criticidade, dos sujeitos que de alguma maneira estão inseridos nela. Assim, a escola deve privilegiar a formação cidadã e a transformação social. É necessário percebermos que ao construir e transmitir conhecimento, a escola também forja sujeitos e subjetividades.

\section{Ser um professor diferente: "pedagogia da inclusão"}

Os valores e os modelos de conduta produzidos na escola e transmitidos por ela, tanto por meio dos conteúdos da educação formal, como através da interação cotidiana com colegas, educadoras/es, estão impregnados de todos os preconceitos e as 
desigualdades que são comuns na sociedade, legitimando-os pelo peso da instituição educativa e pela sanção coletiva da comunidade escolar.

De acordo do Louro (2007) é imprescindível a reinvenção da escola no sentido de colocar em pauta as questões pertinentes à vida dos sujeitos que por ela transitam e se constituem. Nesse sentido, professores relatam,

Eu nunca tinha parado pra pensar a relação entre minha formação, desde a escola, considerando minha orientação sexual e minha prática pedagógica [...] e agora fico pensando que não podemos, posso perder de vista que os tempos são outros, muita coisa mudou. A grande questão é: como eu professor gay estou trabalhando esses assuntos com meus alunos? De cara já posso dizer que sou um professor diferente... acho que o sofrimento contribuiu com minha formação, acho não, tenho certeza. Não posso repeti com meus alunos os mesmos erros que cometeram comigo [...] de alguma forma eu preciso ser diferente, e a universidade ajudou a gente a compreender tudo isso. Mesmo não tendo uma disciplina que fale sobre o assunto, mas os professores em geral são mais abertos a essas questões e isso ajuda, e muito, pra gente ser diferente (Professor Umbuzeiro).

Sabe... eu sofri tanto na escola, por ser gay, que não posso me dar o direito de cometer os mesmos erros. Procuro desenvolver uma prática pedagógica que seja o mais inclusiva possível. Eu chamo de pedagogia da inclusão. A gente vai participa de um curso aqui, outro ali e vai percebendo que é preciso mudar nossa prática, mas te confesso que não é algo fácil. Chega um momento em que a gente fica meio briguento e passa a reivindicar mais direitos [...] e digo sem medo que minha história de vida me ajuda a ser um profissional melhor (Professor Juazeiro).

Nesse sentido, as experiências acima evidenciam que práticas pedagógicas pautadas no respeito ao direito do outro se fazem necessárias. A escola precisa aprender com a diversidade, garantindo assim o direito à liberdade de manifestação sexual ou qualquer forma expressão.

Os excertos apresentados denunciam o descaso e a precariedade nos cursos de formação docente para lidar com as questões de equidade de gênero e sexualidade, já que os professores narram ter uma prática pedagógica inclusiva muito mais por conta da sua orientação sexual que pela sua formação escolar/acadêmica. Desta maneira, as discussões de temáticas referentes à diversidade sexual e aos direitos sexuais nas escolas, necessitam de suporte de políticas públicas na área da educação e de mobilizações sociais que objetivem desestabilizar a produção de hierarquias, opressões e padrões heteronormativos, que histórica e culturalmente moldam as relações de gênero.

Louro (1997) observa que, embora não se possa atribuir à escola o poder e a responsabilidade de explicar identidades sociais ou de determiná-las de forma definitiva, é necessário reconhecer que "[...] suas proposições, suas imposições e proibições fazem sentido, têm 'efeitos de verdade', constituem parte significativa das histórias pessoais" (p.21). Ressaltamos que questionar sobre esses campos não é uma tarefa fácil, olhar para esses discursos de modo diferenciado é colocar em confronto relações de poder. 


\section{À guisa da conclusão}

A reflexão em torno das questões vinculadas à sexualidade no atual contexto ainda é considerada um tabu. Em função da importância que essa temática adquiriu na nossa sociedade, nesse trabalho, buscamos ver e entender como a sexualidade tem sido tratada no ambiente escolar, considerando que a percebemos como uma construção histórica e cultural.

A homossexualidade existe desde a antiguidade. Isso significa que os relatos e escritos permitem construir um olhar aberto em torno da diversidade que existia e que era permissiva, sem maldades e desconforto por parte de quem desejasse assumir essa identidade, a exemplo de Iolaos na Grécia.

Nesse sentido, as narrativas (auto)biográficas contribuíram para uma maior compreensão desse fenômeno nos espaço escolares ao tempo em que possibilitou aos professores um momento de reflexão e auto formação. "Falar sobre mim mesmo, sabendo que isso pode se tornar conhecimento, me leva a refletir sobre minha formação e me dou conta que nada foi em vão" (Professor Juazeiro).

Compreendemos assim, que as narrativas (auto)biográficas, enquanto perspectiva epistemológica se apresentam num instrumento rico de auto formação, uma vez que o ambiente escolar deve se constituir em um espaço e em uma educação menos desigual, mais humanizadora e que potencialize as habilidades humanas, até mesmo no modo de ver que há diferenças, mas reconhecer nelas e, através delas, as qualidades, vislumbres, edificações e dimensões que nos fazem grandes seres humanos.

Conhecer aspectos do percurso da vida pessoal e profissional construído pelos professores Juazeiro e Umbuzeiro, foi uma experiência singular, mesmo considerando o fato de conhecê-los. A narrativa se apresentou numa outra experiência e isso contribuiu significativamente para que realizássemos reflexões ricas e produtivas acerca da formação e das suas trajetórias de vida.

\section{Referências}

ARROYO, M. G. Currículo, Território em Disputa. Rio de Janeiro: Vozes, 2011.

BRITZMAN, D. O que é esta coisa chamada Amor - Identidade homossexual: educação e currículo. Revista Educação e Realidade, Porto Alegre, v. 21. p. 71-96, jan/jun. 1996.

CATANI, D. B. (Org.). Docência, memória e gênero. Estudos sobre a formação. São Paulo: Escrituras Editora, 1997.

FERRAROTTI, F. Sobre a autonomia do método biográfico. In: NÓVOA, A; FINGER, M. O método (auto)biográfico e a formação. EDUFRN, Natal, 2014, p. 29 -55

GAMSON, J. As sexualidades, a teoria queer e pesquisa qualitativa. IN: DENZIN, N. K.; LICOLN, Y. S. et al. O planejamento da pesquisa qualitativa: teorias e abordagens. Trad. Sandra Regina Netz. Porto Alegre: Artmed, 2007.

P. In: DENZIN, N. K.; LICOLN, Y. S. et al. O planejamento da pesquisa qualitativa: teorias e abordagens. Trad. Sandra Regina Netz. Porto Alegre: Artmed, 2007.p. 345-362.

HOUAISS, A; VILLAR, M. de S. Dicionário Houaiss da língua portuguesa. Rio de Janeiro. Objetiva, 2001. 
JOSSO, M. C. Experiências de vida e formação. São Paulo, Cortez, 2004.

LOURO, G. L. O corpo educado: pedagogias da sexualidade. Belo Horizonte: Autêntica.1997.

. Heteronormatividade e Homofobia. Diversidade sexual na educação: problematizações sobre a homofobia nas escolas. Brasília: MEC/Secretaria de Educação Continuada, Alfabetização e Diversidade, UNESCO, 2003.

LOURO, G. L. Um corpo estranho: ensaios sobre sexualidade e teoria queer. Belo Horizonte: Autêntica, 2004. 2007.

Gênero, sexualidade e educação: Uma perspectiva pós-estruturalista. Petrópolis: Vozes,

MOREIRA, D. A. O Método Fenomenológico na Pesquisa. São Paulo: Thompson Pioneira, 2002.

MOTT, L. Homossexualidade: mitos e verdades. Salvador: Ed. Grupo Gay da Bahia, 2003.

NÓVOA, A. Formação de professores e profissão docente. In: NÓVOA, A. (Coord.). Os professores e a sua formação. Lisboa: Dom Quixote, 1992. p. 13-33.

Os professores e as histórias da sua vida. In: . (Org). Vidas de professores. Porto: Porto, 2000, p. 11-30

SCOTT,J. Gênero: uma categoria útil de análise histórica. Educação e Realidade, Porto Alegre, v. 20, n. 2, jul./dez. 1986.

SOUZA, E. C. de. A arte de contar e trocar experiências: reflexões teórico- metodológicas sobre história de vida em formação. Revista Educação em Questão, Natal, v. 25, n. 11, p. 22-39, jan./ abr., 2006.

(Auto)biografia, identidades e alteridade: modos de narração, escritas de si e práticas de formação na pós-graduação. Revista Fórum Identidades, ano 2, volume 4-p. 37-50 - jul-dez de 2008.

Diálogos cruzados sobre pesquisa (auto)biográfica: análise compreensiva-interpretativa e política do sentido. Volume 39. N. 1 - p. 39-50 - jan/abri 2014.

VRISSIMTZIS, N. A. Pederastia. In: São Paulo: Odysseus, 2002. . Amor, Sexo \& Casamento na Grécia Antiga.

\section{Notas}

\footnotetext{
${ }^{1}$ Heteronormatividade deve ser compreendida como a obsessão com a sexualidade normatizante heterossexual, através de discursos que descrevem a situação homossexual como desviante e imoral. Coloca-se desta maneira, segundo Débora Britzman (1996), uma imagem de identidade sexual heterossexual como "normal" e "natural".

${ }^{2}$ O Eromenos (em grego, é $\rho \omega ́ \mu \varepsilon v o \varsigma$ - plural: "eromenoi") era um adolescente do sexo masculino envolvido em uma relação amorosa com um homem adulto, denominado Erastes (em grego, é $\rho \alpha \sigma \tau \eta ́ \varsigma$ - plural: "erastoi"). O relacionamento entre o eromenos e o erastes era muito mais amplo que meramente sexual, como atesta a variação de nomes nas diversas polei. Em Atenas, o eromenos era também chamado "paidika". Em Esparta, era aites ("ouvinte"). Em Creta, era kleinos ("glorioso") (VRISSIMTZIS, 2002).

${ }^{3}$ Grupo de Estudo acerca das identidades de Gênero e Sexualidades, constituído formado por professores/ as e estudantes da Universidade do Estado da Bahia - UNEB, Campus VII.

${ }^{4}$ O Juazeiro também conhecido por joá, laranjeira-de-vaqueiro, juá-fruta, juá e juá-espinho, é uma árvore típica do Semiárido Brasileiro, conhecida por resistir a grandes períodos de estiagem. A árvore é reputada
} 
por diversas propriedades medicinais. Entre seus componentes químicos, destacam-se vitamina C, pó de juá, cafeína, ácido betulínico e saponinas (estas últimas consideradas tóxicas, se ingeridos em grandes quantidades). O extrato do juazeiro, o juá, é empregado na indústria farmacêutica em produtos cosméticos, dentre eles xampus e cremes, bem como em cremes dentais.

${ }^{5}$ É uma árvore de pequeno porte, originária dos chapadões Semiáridos do Nordeste brasileiro, que se destaca por fornecer sombra e aconchego. Dada a importância de suas raízes, é conhecida como a "árvore sagrada do Sertão". O umbuzeiro conserva água em sua raiz, podendo chegar a armazenar até mil litros, e, além disso, produz uma batata, que, em época de grande estiagem, é utilizada como alimento. O umbuzeiro vive em média 100 anos, e é considerado um símbolo de resistência. Seu fruto é conhecido como umbu ou imbu e possui grande importância econômica, uma vez que são bastante comercializados. Suas folhas e raízes também podem ser utilizadas para alimentação e, além disso, a água armazenada nesta última é utilizada na medicina popular.

${ }^{6}$ Expressão muito utilizada no universo gay. Que significa muito mais do que "fechar", zerar tudo, destacarse entre os demais.

* Professor da Universidade do Estado da Bahia, Senhor do Bonfim, Bahia, Brasil.

** Professora doutora da Universidade do Estado da Bahia, Senhor do Bonfim, Bahia, Brasil.

*** Professor da Universidade do Estado da Bahia, Senhor do Bonfim, Bahia, Brasil.

\section{Correspondência}

Pedro Paulo Souza Rios - Universidade do Estado da Bahia, Departamento de Ciências Humanas Campus VII. BR 407 - Centro. CEP: 44770000. Senhor do Bonfim, Bahia, Brasil.

E-mail: peudesouza@yahoo.com.br-ebarros@uneb.br - sistlin@uol.com

Recebido em 28 de novembro de 2016

Aprovado em 17 de abril de 2017 
